Check for updates

Cite this: RSC Adv., 2017, 7, 32038

Received 20th April 2017

Accepted 15th June 2017

DOI: $10.1039 / \mathrm{c} 7 \mathrm{ra0} 4481 \mathrm{j}$

rsc.li/rsc-advances

\title{
Electrodeposition: a versatile, efficient, binder-free and room temperature one-step process to produce $\mathrm{MnO}_{2}$ electrochemical capacitor electrodes $\dagger$
}

\author{
R. Della Noce, (D) *a S. Eugénio, ${ }^{a}$ T. M. Silva, ${ }^{\text {ab }}$ M. J. Carmezim ${ }^{\text {ac }}$ and M. F. Montemor ${ }^{a}$
}

The use of room temperature cathodic electrodeposition to produce $\mathrm{MnO}_{2}$ electrochemical capacitor electrodes is demonstrated. By employing a permanganate-based bath, birnessite-type $\mathrm{MnO}_{2}$ electrodes are directly obtained with no further heat treatment. Moreover, a crystalline/amorphous structural transition is observed as the applied current density is increased up to $50 \mathrm{~mA} \mathrm{~cm}^{-2}$.

\section{Introduction}

Manganese oxides are multifunctional materials that display a myriad of applications in advanced catalysis, ${ }^{1}$ Li-ion rechargeable batteries, ${ }^{2,3}$ microbial fuel cells, ${ }^{4,5}$ and electrochemical capacitors. ${ }^{6,7}$ They have been produced by a variety of chemical and physical methods such as hydrothermal synthesis, ${ }^{8}$ sol-gel process, ${ }^{9}$ physical vapor deposition (PVD), ${ }^{10}$ chemical vapor deposition (CVD), ${ }^{11}$ and electrodeposition. ${ }^{12}$ Among these techniques, electrodeposition has stood out mainly owing to its cost-effectiveness, relatively low temperature operating conditions, lower energy and space requirement, and easily maintained equipment. In fact, Dini showed that PVD processes may be as much as ten times more costly than electrodeposition. ${ }^{13}$ Electrodeposition also allows the deposition of the active material directly on the current collector, eliminating the need for binders and extra-process steps. Furthermore, thickness, and structural and morphological properties of the deposits can be tailored by relatively simple parameters such as potential, current density, bath concentration, $\mathrm{pH}$, and temperature.

The fabrication of electrodeposited manganese oxides, in particular $\mathrm{MnO}_{2}$, has been demonstrated by two main routes: ${ }^{6,14}$

(1) Anodic deposition: by employing sulfate-, nitrate or acetate-based baths according to the following reaction:

$$
\mathrm{MnO}_{2}+4 \mathrm{H}^{+}+2 \mathrm{e}^{-} \rightleftharpoons \mathrm{Mn}^{2+}+2 \mathrm{H}_{2} \mathrm{O} E^{0}=1.224 \mathrm{~V}
$$

where $\mathrm{Mn}$ (II) ions are oxidized to Mn(Iv) species leading to the formation of the manganese dioxide. Note that the reaction is

${ }^{a}$ Centro de Quimica Estrutural-CQE, Departament of Chemical Engineering, Instituto Superior Técnico, Universidade de Lisboa, 1049-001 Lisboa, Portugal. E-mail: rodrigo.noce@tecnico.ulisboa.pt

${ }^{b}$ Department of Mechanical Engineering, GI-MOSM, Instituto Superior de Engenharia de Lisboa, 1950-062 Lisboa, Portugal

${ }^{c}$ ESTSetúbal, Instituto Politécnico de Setúbal, 1959-007 Setúbal, Portugal

$\dagger$ Electronic supplementary information (ESI) available: SEM images and XRD. See DOI: $10.1039 / \mathrm{c} 7 \mathrm{ra} 04481 \mathrm{j}$ written in the reverse way since the standard reduction potential is shown. ${ }^{15}(2)$ Cathodic electrodeposition: one-step deposition from permanganate $\left(\mathrm{MnO}_{4}^{-}\right)$bath:

$$
\mathrm{MnO}_{4}^{-}+2 \mathrm{H}_{2} \mathrm{O}+3 \mathrm{e}^{-} \rightleftharpoons \mathrm{MnO}_{2}+4 \mathrm{OH}^{-} E^{0}=0.595 \mathrm{~V}
$$

where $\mathrm{Mn}$ (VII) ions are directly reduced to $\mathrm{Mn}$ (Iv) species. Besides these two purely electrochemical approaches, another commonly employed in literature involves a cathodic deposition step plus a chemical one. By applying potential or current from nitrate- or acetate-based bath manganese hydroxide is initially formed as follows:

$$
\mathrm{Mn}^{2+}+2 \mathrm{OH}^{-} \rightarrow \mathrm{Mn}(\mathrm{OH})_{2}
$$

After subsequent heat treatment, which in general is done at about $300{ }^{\circ} \mathrm{C},{ }^{16}$ to dehydrate the manganese hydroxide, $\mathrm{MnO}_{2}$ is finally obtained.

In this work, the use of room temperature cathodic electrodeposition to produce $\mathrm{MnO}_{2}$ electrochemical capacitor (EC) electrodes is reported. By employing permanganate $\left(\mathrm{MnO}_{4}{ }^{-}\right)$based bath, birnessite-type $\mathrm{MnO}_{2}$ electrodes are directly obtained with no further heat treatment. Although, some papers have described the production of $\mathrm{MnO}_{2} \mathrm{EC}$ electrodes by this method, ${ }^{12,14,17}$ as far as we know, the influence of the applied current density on the structure and capacitive performance of $\mathrm{MnO}_{2}$ electrodes has not yet been described. Here, it is demonstrated by means of X-ray diffractometry (XRD) that a crystalline/amorphous structural transition is observed as the applied current density is increased up to $50 \mathrm{~mA} \mathrm{~cm}{ }^{-2}$.

\section{Experimental}

\section{1. $\mathrm{MnO}_{2}$ electrodeposition}

$\mathrm{MnO}_{2}$ was galvanostatically electrodeposited onto stainless steel (AISI 304, Goodfellow) from a bath composed of $0.01 \mathrm{M}$ $\mathrm{KMnO}_{4}$ and $0.1 \mathrm{M} \mathrm{Na}_{2} \mathrm{SO}_{4}$. The bath $\mathrm{pH}$ was set to 7 by adding 
dilute $\mathrm{NaOH}$. Analytical grade chemicals were used to prepare all solutions. The $\mathrm{MnO}_{2}$ deposits were obtained by using a Gamry Interface $5000 \mathrm{E}$ potentiostat/galvanostat at room temperature. A three-electrode conventional cell was used for all electrochemical experiments. The applied current density $\left(i_{\mathrm{c}}\right)$ was varied from 0.5 up to $50 \mathrm{~mA} \mathrm{~cm}{ }^{-2}$ maintaining the same charge density $\left(2 \mathrm{C} \mathrm{cm}^{-2}\right)$. The mass of $\mathrm{MnO}_{2}$ deposits was directly measured using an electronic microbalance (Sartorius, model MC $5 d=0.01 / 0.1 \mathrm{mg}$ ). The mass loading of the active material was obtained in all cases by subtracting the substrate mass from the total weight. In general, the mass loading of the deposits ranged from 0.3 to $1.45 \mathrm{mg}$.

\subsection{Morphological and structural characterization}

The morphology of the deposits was characterized by scanning electron microscopy (SEM) using a JEOL model JSM-7001F field emission gun SEM equipped with energy dispersive $\mathrm{X}$ ray spectroscopy (EDX). The X-ray diffractometry (XRD) measurements were performed using $\mathrm{Cu} \mathrm{K} \alpha$ radiation $(1.5418$ A) in a Bruker AXS D8 Advance instrument at $0.002^{\circ} \mathrm{s}^{-1}$ scan rate, a slow scan rate to avoid peak widening. Raman spectra were acquired (Horiba LabRAM HR800 Evolution) using the radiation source with a solid-state laser operating at $532 \mathrm{~nm}$ with an output power of $20 \mathrm{~mW}$. The Raman band of a silicon wafer at $520 \mathrm{~cm}^{-1}$ was used to calibrate the spectrometer. The spectra were collected between 200 and $800 \mathrm{~cm}^{-1}$ with the sample exposed to the air under ambient conditions and obtained with an acquisition time of $30 \mathrm{~s}$ and 15 accumulations. A spectrograph with a 600 lines per mm grating was used. A 50 times objective lens focused the laser beam on the sample surface.

\subsection{Electrochemical characterization}

The electrochemical performance of $\mathrm{MnO}_{2} / \mathrm{SS}$ electrodes was assessed by cyclic voltammetry (CV) and chronopotentiometry (charge-discharge curves). A platinum plate and a saturated calomel electrode (SCE) were used as counter and reference electrodes, respectively. All the experiments were performed in freshly prepared $1 \mathrm{M} \mathrm{Na}_{2} \mathrm{SO}_{4}$ electrolyte at room temperature. Charge-discharge curves were conducted in a potential range from -0.1 to $0.9 \mathrm{~V}$ applying a specific current of $1 \mathrm{~A} \mathrm{~g}^{-1}$. Furthermore, a long-term cycling test constituted of 5000 cycles at $5 \mathrm{Ag}^{-1}$ was carried out to verify the $\mathrm{MnO}_{2} / \mathrm{SS}$ electrode $\left(i_{\mathrm{c}}=50\right.$ $\mathrm{mA} \mathrm{cm}{ }^{-2}$ ) stability. No conditioning was performed prior to the long-term cycling test.

\section{Results and discussion}

Fig. 1 displays the potential vs. time $(E \times t)$ profiles for the galvanostatic electrodeposition of $\mathrm{MnO}_{2}$ onto SS by applying different current densities in the range 0.5 to $50 \mathrm{~mA} \mathrm{~cm}{ }^{-2}$. The potential increases with $i_{\mathrm{c}}$, reaching a maximum of about $5 \mathrm{~V}$ at $i_{\mathrm{c}}=50 \mathrm{~mA} \mathrm{~cm}^{-2}$. When $i_{\mathrm{c}}=0.5 \mathrm{~mA} \mathrm{~cm}^{-2}$, no $\mathrm{MnO}_{2}$ deposition takes place and then, it can be inferred that $\mathrm{MnO}_{2}$ is only formed for higher $i_{\mathrm{c}}$ values.

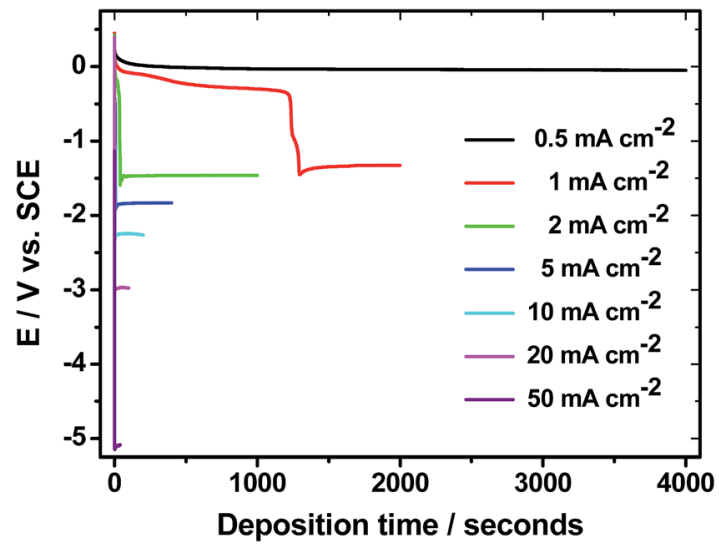

Fig. $1 E-t$ profiles for the electrodeposition of $\mathrm{MnO}_{2}$ onto SS by applying different applied current densities. Total charge density: $2 \mathrm{C} \mathrm{cm}^{-2}$.

By using Faraday's law of electrolysis, it is possible to estimate the global current efficiency of the $\mathrm{MnO}_{2}$ electrodeposition process as follows: ${ }^{18}$

$$
m=Q M /(F z)
$$

where $m$ is the expected mass of $\mathrm{MnO}_{2}$ deposit, $Q$ (Coulombs) is the total quantity of electric charge for the $\mathrm{MnO}_{2}$ electrochemical deposition, $F$ is the Faraday constant which is equal to $96485 \mathrm{C} \mathrm{mol}^{-1}, M\left(\mathrm{~g} \mathrm{~mol}{ }^{-1}\right)$ is the molecular weight of $\mathrm{MnO}_{2}$ and $z$ is the number of electrons transferred from $\mathrm{Mn}^{7+}$ to $\mathrm{Mn}^{4+}$. As the mass of the deposits is known, the current efficiency of the $\mathrm{MnO}_{2}$ electrochemical process can be calculated as summarized in Table 1.

As expected, increasing $i_{\mathrm{c}}$ leads to a decrease of the current efficiency due to the increase of hydrogen evolution reaction. The deposit obtained at $1 \mathrm{~mA} \mathrm{~cm}{ }^{-2}$ shows a current efficiency close to $100 \%$. In fact, in industrial electroplating processes, a high current efficiency is always desirable in order to minimize the electricity consumption. Considering the $\mathrm{MnO}_{2}$ density as $5.03 \mathrm{~g} \mathrm{~cm}^{-3}$, the deposits thickness can be also obtained (Table 1). For the same reason, i.e. hydrogen evolution reaction, the deposits thickness decreases as $i_{\mathrm{c}}$ increases, ranging from ca. $1.2 \mu \mathrm{m}$ to $250 \mathrm{~nm}$. Nevertheless, for these

Table 1 Current efficiency (CE) and thickness of $\mathrm{MnO}_{2}$ deposits obtained by modulating the applied current density in the range 1$50 \mathrm{~mA} \mathrm{~cm}{ }^{-2}$. The thickness of the $\mathrm{MnO}_{2}$ deposits was estimated by taking into account the $\mathrm{MnO}_{2}$ density $\left(5.03 \mathrm{~g} \mathrm{~cm}^{-3}\right)$ and also by SEM images of the cross-section of the $\mathrm{MnO}_{2}$ deposits. Total charge density: $2 \mathrm{C} \mathrm{cm}^{-2}$

\begin{tabular}{lllll}
\hline$i / \mathrm{mA} \mathrm{cm}^{-2}$ & $\begin{array}{l}\text { Deposited } \\
\text { mass } / \mathrm{mg}\end{array}$ & $\mathrm{CE} / \%$ & $\begin{array}{l}\text { Thickness/ } \\
\mu \mathrm{m}\end{array}$ & $\begin{array}{l}\text { Thickness } \\
(\mathrm{SEM}) / \mu \mathrm{m}\end{array}$ \\
\hline 1 & 1.45 & 96.6 & 1.15 & - \\
2 & 1.05 & 69.9 & 0.83 & 6.4 \\
5 & 0.80 & 53.3 & 0.64 & 3.9 \\
10 & 0.65 & 43.3 & 0.52 & 2.3 \\
20 & 0.50 & 33.3 & 0.40 & 2.0 \\
50 & 0.30 & 20.0 & 0.25 & 0.9
\end{tabular}


thicknesses calculations is assumed that the formed films are not porous which is not verified when SEM images (Fig. 2 and 3) are analyzed. For this reason, cross-section SEM images of the $\mathrm{MnO}_{2} / \mathrm{SS}$ electrodes have been performed to obtain more realistic values of the deposits thickness, which are also displayed in Table 1. In this case, the values of thickness range from approximately 6.4 to $0.9 \mu \mathrm{m}$ for the deposits obtained at $i_{\mathrm{c}}=2$ and $50 \mathrm{~mA} \mathrm{~cm}{ }^{-2}$, respectively. These values are different from those previously obtained from $\mathrm{MnO}_{2}$ density consideration and can be explained based on the porosity of the deposits. The same trend, i.e. the deposits thickness decreases as $i_{\mathrm{c}}$ increases, is observed in the case of the thicknesses estimation by crosssection SEM images of the $\mathrm{MnO}_{2} / \mathrm{SS}$ electrodes. If thicker films are desirable, porous substrates can be employed. Indeed, $\mathrm{Su}$ and Zhitomirsky ${ }^{19}$ have recently demonstrated that $\mathrm{MnO}_{2}$ electrodes with mass loading of $13 \mathrm{mg} \mathrm{cm}{ }^{-2}$ can be successfully electrodeposited by utilizing a porous Ni plaque as substrate. Most of works related to $\mathrm{MnO}_{2}$ and other ECs electrodes has been devoted to obtain high mass loadings (on the order of $\left.10 \mathrm{mg} \mathrm{cm}^{-2}\right)^{20}$ materials required for commercial applications, nevertheless, thin films EC electrodes technology has successfully emerged in last decades. In this sense, electrodeposited thin films electrodes have been utilized in semiconductor devices, integrated circuit fabrication, and multilayer ceramic substrates. In these cases, it is difficult to obtain large specific capacitance (SC) values (e.g. $\left.>0.1 \mathrm{mF} \mathrm{cm}^{-2}\right)$ with electrostatic capacitor technology but quite easy with using EC technology. Voltage in such circuits is relatively low in which an aqueous electrolyte device as a single cell, especially if of the asymmetric

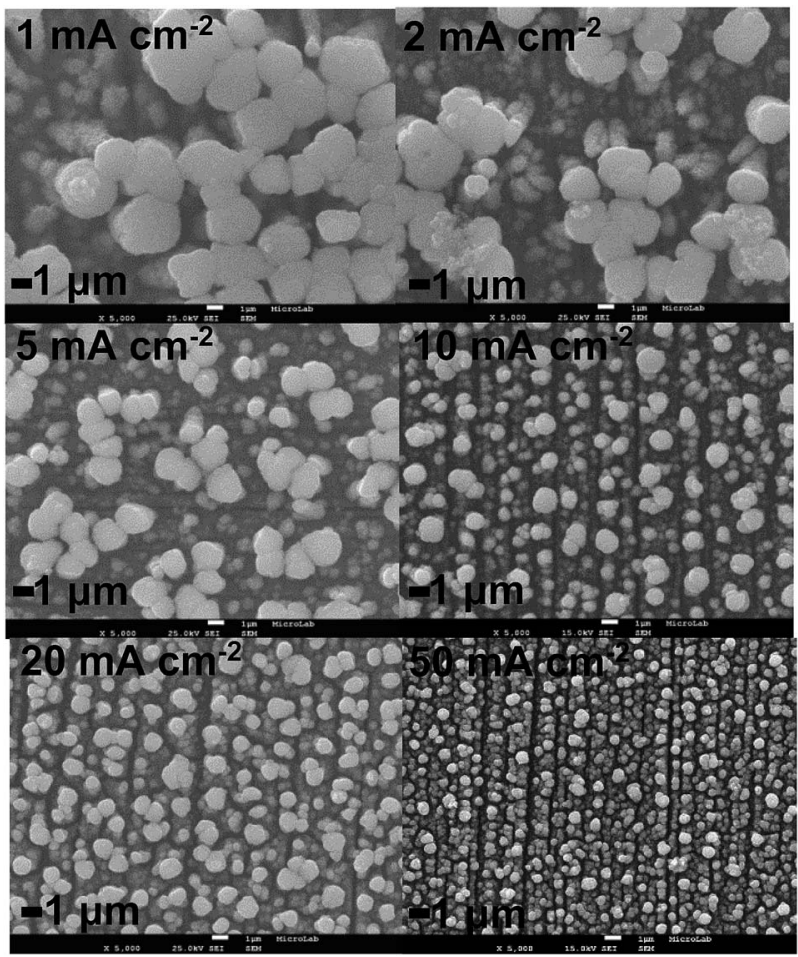

Fig. 2 Top-view SEM images of $\mathrm{MnO}_{2} / \mathrm{SS}$ electrodes obtained at various $i_{\mathrm{c}}$.

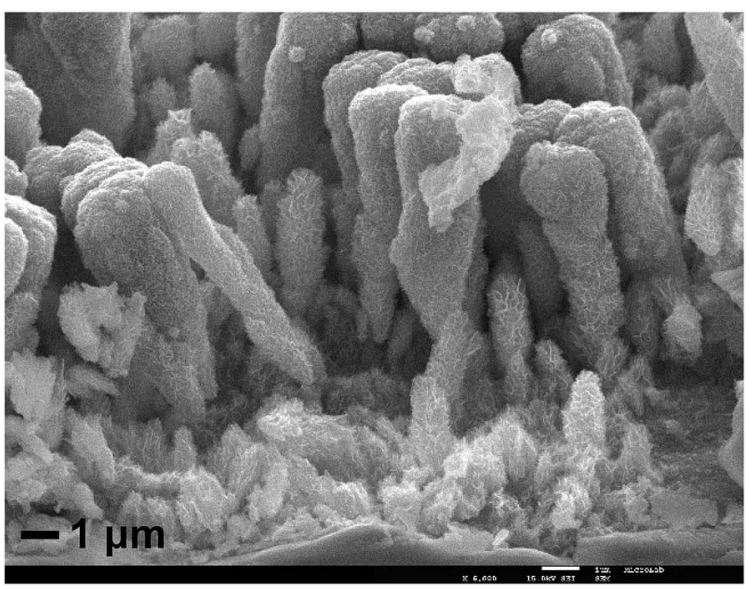

Fig. 3 Cross-section SEM image of $\mathrm{MnO}_{2} / \mathrm{SS}$ electrode obtained at $2 \mathrm{~mA} \mathrm{~cm}^{-2}$

design, will have sufficient operating voltage. In addition, the most popular process nowadays used to make EC electrodes (both in laboratory and in industry) is slurry coating, which is limited in its minimum thickness to the size of particles in the slurry, typically 1 to 5 micrometers. By employing electrodeposition, much thinner electrodes, even approaching few nanometers thickness, can be obtained. Therefore, electrodeposition can be considered as an efficient and versatile technique to produce either thin or thick $\mathrm{MnO}_{2}$ EC electrodes by simply modulating the applied current density. In order to analyze the morphology of $\mathrm{MnO}_{2} / \mathrm{SS}$ electrodes, scanning microscopy electron (SEM) has been employed. Fig. 2 depicts the top-view SEM images of $\mathrm{MnO}_{2}$ electrodeposits obtained at various $i_{\mathrm{c}}$. Microspheres are noticed along the whole deposit which are indeed composed of nanoflakes, as shown in Fig. 1S, $\uparrow$ under high magnification. In fact, $\mathrm{MnO}_{2}$ nanoflakes electrodes have been obtained by anodic electrodeposition as recently reported by Mai et al. ${ }^{21}$ Moreover, it is clear that a grain refinement occurs as $i_{\mathrm{c}}$ increases leading to the formation of reduced grains at higher $i_{\mathrm{c}}$ values (see Fig. $2 \mathrm{~S}$ in ESI $\dagger$ ).

As mentioned above, cross-section SEM images have been acquired in order to estimate the deposits thickness. Fig. 3 illustrates the cross-section SEM image of $\mathrm{MnO}_{2} / \mathrm{SS}$ electrode obtained at $2 \mathrm{~mA} \mathrm{~cm}{ }^{-2}$. The average thickness in this case is about $6.4 \mu \mathrm{m}$. The average thickness values for the deposits obtained in the range $2-50 \mathrm{~mA} \mathrm{~cm}{ }^{-2}$ are listed in Table 1 .

XRD and Raman Spectroscopy have been utilized to determine the structure of the $\mathrm{MnO}_{2} / \mathrm{SS}$ electrodes. Fig. 4 a shows the XRD patterns of $\mathrm{MnO}_{2} / \mathrm{SS}$ electrodes obtained for $i_{\mathrm{c}}$ values in the range $1-50 \mathrm{~mA} \mathrm{~cm}^{-2}$. The samples obtained at $i_{\mathrm{c}}<20 \mathrm{~mA} \mathrm{~cm}{ }^{-2}$ exhibit two main peaks at $12.4^{\circ}$ and $24.8^{\circ}$, and one broad peak at $36.9^{\circ}$ which correspond to (001), (002) and (020) planes of the $\delta-\mathrm{MnO}_{2}$ (JCPDS no. 18-0802) confirming the Na-birnessite structure formation. ${ }^{12,22}$ It is important to highlight that the Na-birnessite structure, obtained in this work, is only stabilized by the presence of $\mathrm{Na}^{+}$cations which is present in the electrochemical bath. If no $\mathrm{Na}_{2} \mathrm{SO}_{4}$ is initially present, amorphous electrodeposits are achieved as illustrated in Fig. $3 \mathrm{~S}, \dagger$ for 

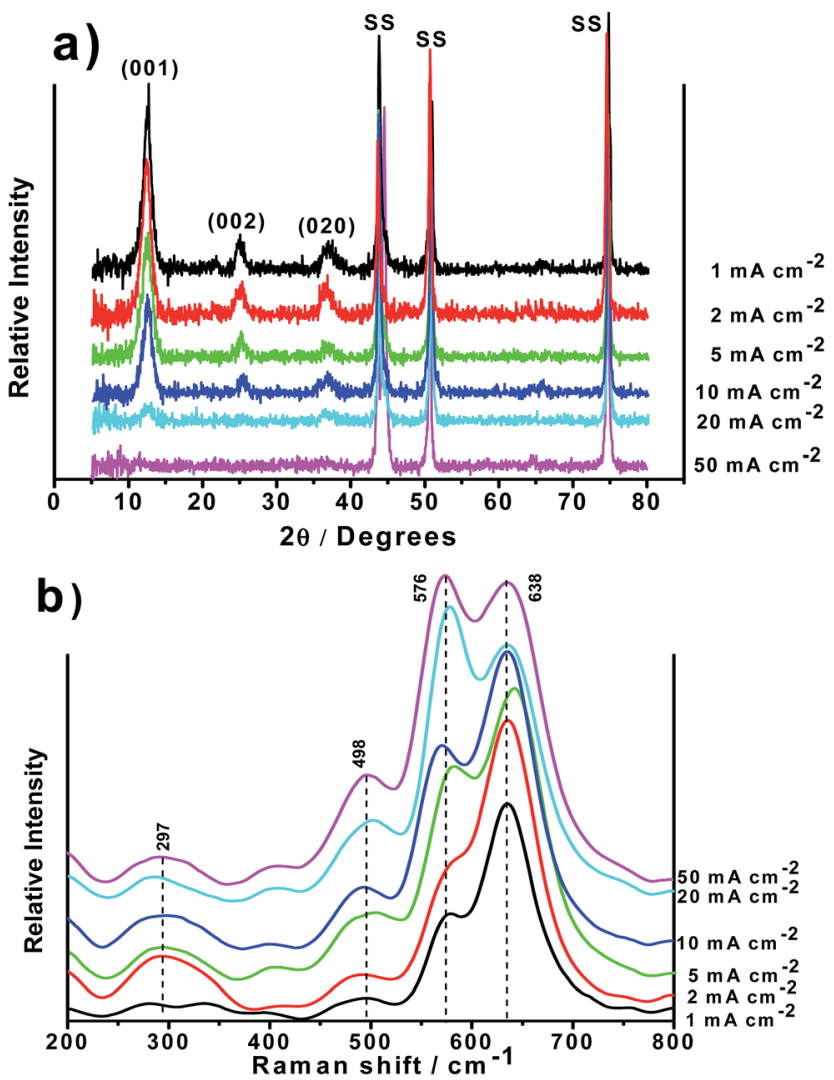

Fig. 4 XRD patterns (a) and Raman spectra (b) of birnessite-type $\mathrm{MnO}_{2} / \mathrm{SS}$ electrodes obtained at various $i_{\mathrm{c}}$.

a sample prepared under the same conditions except the $\mathrm{Na}_{2} \mathrm{SO}_{4}$ addition to the bath. This observation is in full agreement with the work reported by Tanimoto et al. ${ }^{12}$ that obtained K-birnessite $\mathrm{MnO}_{2}$ electrodes from a $\mathrm{MnO}_{4}$-based bath containing $\mathrm{K}^{+}$ions. In addition, the XRD patterns show an amorphous (absence of long range order) state for the samples obtained at $i_{\mathrm{c}}=20$ and $50 \mathrm{~mA}$ $\mathrm{cm}^{-2}$. This is attributed to the effect of grain refinement (decreased particle size) as $i_{\mathrm{c}}$ increases, as confirmed by SEM analysis (Fig. 2), which leads to diffraction peak broadening that, ultimately, are not detectable anymore by XRD. The crystalline or amorphous nature of the electrodeposited materials might influence the capacitive performance of the electrodes as will be described below. With regard to the Raman spectra, depicted in Fig. $4 \mathrm{~b}$, four major vibrational features corresponding to $\mathrm{MnO}_{2}$ are observed at 297, 498, 576 and $638 \mathrm{~cm}^{-1}$. The band at $576 \mathrm{~cm}^{-1}$ is related to the Mn-O stretching vibration in the basal plane of $\left[\mathrm{MnO}_{6}\right]$ sheets while the band located at $638 \mathrm{~cm}^{-1}$ is attributed to the symmetric $\mathrm{Mn}-\mathrm{O}$ stretching vibration of $\mathrm{MnO}_{6}$ groups. ${ }^{23}$ The bands at 297 and $498 \mathrm{~cm}^{-1}$ are of weak intensity as previously reported by Julien et al. ${ }^{23}$ and may not be visible depending on the preparation method.

The capacitive performance of the prepared $\mathrm{MnO}_{2} / \mathrm{SS}$ electrodes has been analyzed by cyclic voltammetry and chronopotentiometry (charge-discharge curves) in $1 \mathrm{M} \mathrm{Na}_{2} \mathrm{SO}_{4}$ solution. Fig. 5a exhibits the cyclic voltammograms (CVs) of the different $\mathrm{MnO}_{2} / \mathrm{SS}$ electrodes in $1 \mathrm{M} \mathrm{Na}_{2} \mathrm{SO}_{4}$. All CVs show a near-rectangular shape typical of $\mathrm{MnO}_{2}$ materials with
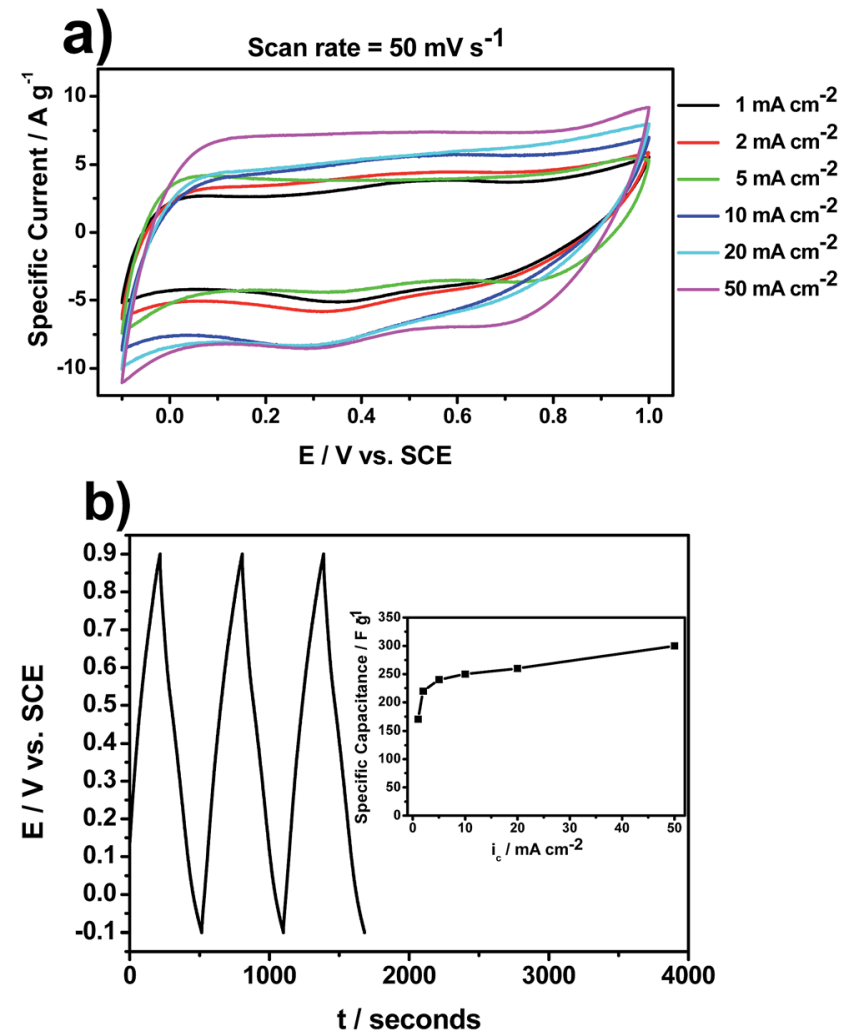

Fig. $5 \mathrm{CVs}$ of $\mathrm{MnO}_{2} / \mathrm{SS}$ electrodes obtained at various $i_{\mathrm{c}}$ (a). Typical charge-discharge curve for $\mathrm{MnO}_{2} / \mathrm{SS}$ electrode obtained at $i_{\mathrm{c}}=50 \mathrm{~mA}$ $\mathrm{cm}^{-2}$ (b). Inset shows the variation of specific capacitance as function of $i_{c}$ for all studied $\mathrm{MnO}_{2} / \mathrm{SS}$ electrodes. Electrolyte: $1 \mathrm{M} \mathrm{Na}_{2} \mathrm{SO}_{4}$.

a working potential window of $1.1 \mathrm{~V}$. In addition, it is noticed that the specific current increases as $i_{\mathrm{c}}$ also increases. This is an indication of higher electrochemical activity which in turn leads to higher materials specific capacitance (inset of Fig. 5b). Knowing the potential limits from CVs, charge-discharge curves have been performed. A characteristic charge-discharge curve of $\mathrm{MnO}_{2} / \mathrm{SS}$ electrode obtained at $i_{\mathrm{c}}=50 \mathrm{~mA} \mathrm{~cm}{ }^{-2}$ is illustrated in Fig. $5 \mathrm{~b}$. All curves, regardless $i_{\mathrm{c}}$, present the same behavior, a near-triangular curve, with an operating working potential of $1 \mathrm{~V}$, which is representative of pseudocapacitive materials such as $\mathrm{MnO}_{2}$ and $\mathrm{RuO}_{2} \cdot{ }^{24}$ The materials SC calculated from charge-discharge curves, shown in the inset of Fig. $4 \mathrm{~b}$, exhibits values from 170 up to $300 \mathrm{~F} \mathrm{~g}^{-1}$ depending on $i_{\mathrm{c}}$. These SC values are comparable to those found in literature for similar synthetic conditions. ${ }^{14,25}$ For instance, Jacob and Zhitomirsky showed that electrodeposited $\mathrm{MnO}_{2}$ films, prepared by cathodic reduction of $\mathrm{KMnO}_{4}$ solutions, with thickness ranging from 0.1 to $2 \mu \mathrm{m}$, display SC values up to 279 $\mathrm{F} \mathrm{g}^{-1}{ }^{14}$ In other work, the same group studied the effect of heat treatment on the $\mathrm{MnO}_{2} / \mathrm{SS}$ electrodes obtained by cathodic electrodeposition at $2 \mathrm{~mA} \mathrm{~cm}{ }^{-2}$. The highest $\mathrm{SC}$ of $\sim 353 \mathrm{~F} \mathrm{~g}^{-1}$ was obtained for the $45 \mu \mathrm{g} \mathrm{cm}^{-2}$ film at a scan rate of $2 \mathrm{mV} \mathrm{s}^{-1}$. The capacitance decreased with increasing scan rate and film thickness. Heat treatment at $200{ }^{\circ} \mathrm{C}$ resulted in the reduced porosity and enhanced crystallinity of the films. Compared to the as-prepared films, the films heat treated at $200{ }^{\circ} \mathrm{C}$ exhibited 
lower SC at scan rates below $10 \mathrm{mV} \mathrm{s}^{-1}$ and higher SC at scan rates above $10 \mathrm{mV} \mathrm{s}^{-1} .^{25}$

It is evident that the deposits thickness plays an important role on SC since $\mathrm{MnO}_{2}$ displays in general poor electrical conductivity, ${ }^{6}$ hence, a decrease in film thickness leads to an increase in SC. As a matter of fact, it has been demonstrated that $\mathrm{MnO}_{2}$ thin films can display high gravimetric capacitances, e.g. in some cases higher than $2000 \mathrm{~F} \mathrm{~g}^{-1}$, which strongly depends on the preparation method. ${ }^{26}$ The SC value in $\mathrm{MnO}_{2}$ films has been depicted to decrease with increasing film thickness, mostly owing to a combination of reduced electrolyte access and increased distance from the current collector, which lead to increased electrical resistance. ${ }^{27}$ Additionally, the grain refinement and more amorphous structure that occurs in the electrodeposited films with increasing $i_{\mathrm{c}}$ also contributes to the higher SC values achieved. It has been reported that the NiO SC from bulk contribution may be at least three times larger in amorphous than in crystalline films for the same surface area. ${ }^{28}$ Therefore, in the case of $\mathrm{MnO}_{2}$-based materials, besides thickness (mass loading), is also important to tailor the crystallinity to exploit their full potential in order to increase SC.

Besides SC, which plays a pivotal role to increase EC's energy density, two other important parameters to evaluate ECs performance are the rate capability and cyclability. Fig. 6a displays the rate capability for all prepared $\mathrm{MnO}_{2} / \mathrm{SS}$ electrodes performed from 1 to $10 \mathrm{~A} \mathrm{~g}^{-1}$. In all cases, there is a considerable decrease in SC as the current density increases which seems to be more pronounced in the samples prepared at low values of $i_{\mathrm{c}}$. For example, in the case of the sample prepared at $50 \mathrm{~mA} \mathrm{~cm}^{-2}$, about $60 \%$ of its SC is retained while for $i_{\mathrm{c}}=1 \mathrm{~mA}$ $\mathrm{cm}^{-2}$ the SC retention is only $45 \%$.

As mentioned above, this is due to the $\mathrm{MnO}_{2}$ poor electrical conductivity that directly affects the electrodes SC. If one desires to circumvent this $\mathrm{MnO}_{2}$ drawback, in order to obtain high
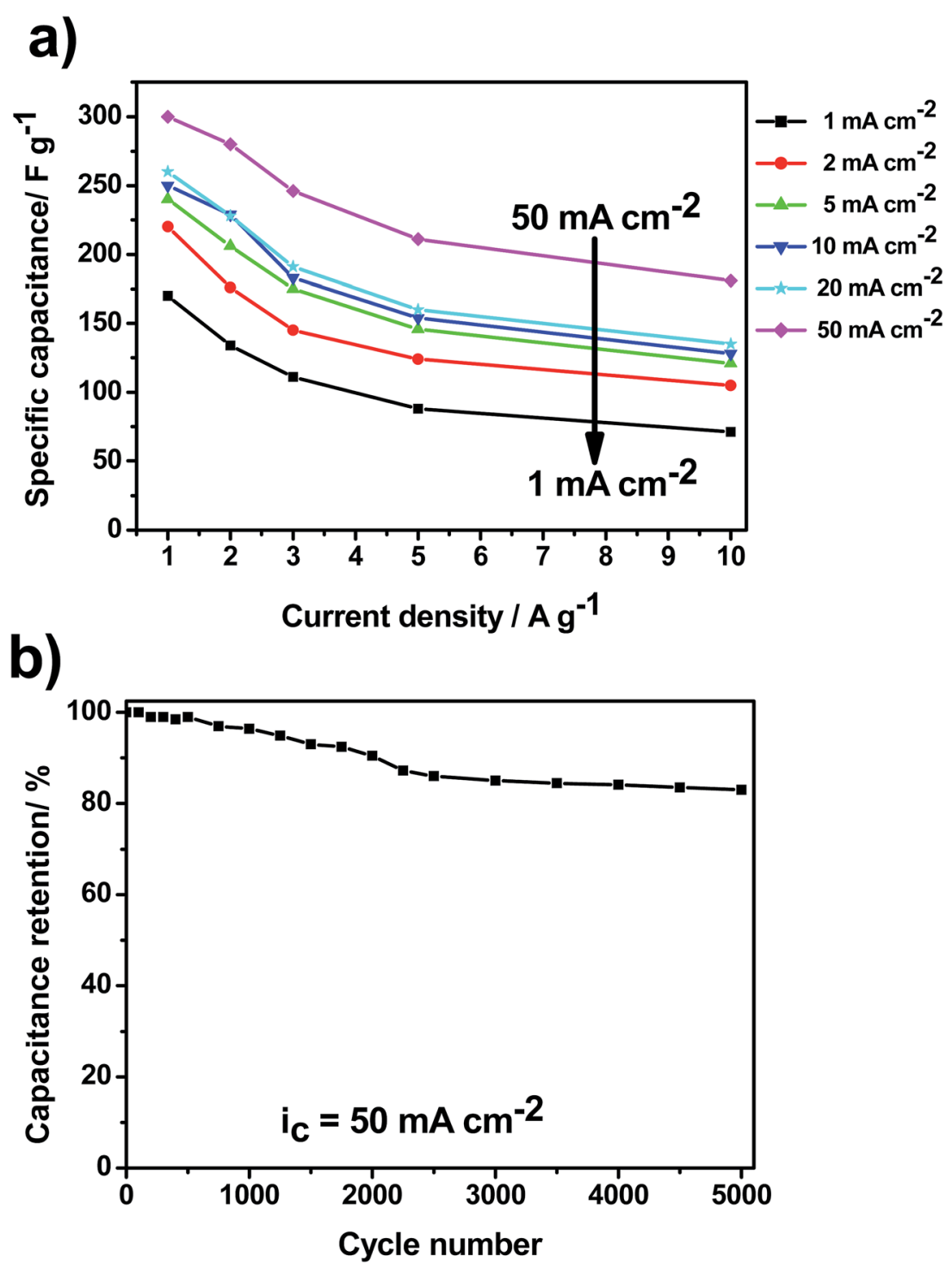

Fig. 6 Rate capability at various current densities for all prepared $\mathrm{MnO}_{2} / \mathrm{SS}$ electrodes (a). Capacitance retention as a function of cycle number for the $\mathrm{MnO}_{2} / \mathrm{SS}$ electrode prepared at $50 \mathrm{~mA} \mathrm{~cm}{ }^{-2}$ by applying $5 \mathrm{~A} \mathrm{~g}^{-1}$ (b). 
performance EC materials, three well-established strategies might be used: ${ }^{6}(1)$ production of mixed oxides: transition metal elements, such as $\mathrm{Ni}, \mathrm{Cu}, \mathrm{Fe}, \mathrm{V}, \mathrm{Co}, \mathrm{Mo}$ and $\mathrm{Ru}$, can be incorporated to $\mathrm{MnO}_{2}$ enhancing the electrical conductivity and charge-storage capability of the resulting mixed oxide, (2) $\mathrm{MnO}_{2}$ doping: $\mathrm{MnO}_{2}$ modified electrodes can be doped with small amount of other metallic elements, e.g., $\mathrm{Al}, \mathrm{Sn}$ and $\mathrm{Pb}$ which leads to a significant increase on the electronic conductivity and, consequently, on the specific capacitance and rate capacity, and (3) formation of composite electrodes: utilization of porous architectures such as carbon nanofoams, templated mesoporous carbon and nanographite, to form $\mathrm{MnO}_{2}$ /carbonbased composite electrodes. In this approach, carbon not only acts as the physical support of $\mathrm{MnO}_{2}$ but also gives rise to channels for charge transport. Its high electronic conductivity enhances the rate capability and power density at large charge/ discharge currents. ${ }^{29}$ With regard to $\mathrm{MnO}_{2} / \mathrm{SS}$ electrodes cyclability, a long-term test performing 5000 cycles at $5 \mathrm{~A} \mathrm{~g}^{-1}$ has been carried out in $1 \mathrm{M} \mathrm{Na}_{2} \mathrm{SO}_{4}$ solution. Fig. $6 \mathrm{~b}$ shows the capacitance retention as a function of cycle number for the sample obtained at $50 \mathrm{~mA} \mathrm{~cm} \mathrm{~cm}^{-2}$. Capacitance retention of $\mathrm{ca}$. $83 \%$ is noticed after 5000 cycles indicating an excellent cycle life under the proposed experimental conditions.

\section{Conclusions}

In summary, the use of room temperature cathodic electrodeposition to produce $\mathrm{MnO}_{2}$ electrochemical capacitor electrodes has been demonstrated. By employing a permanganate-based bath, birnessite-type $\mathrm{MnO}_{2}$ electrodes are directly obtained with no further heat treatment. In addition, the influence of applied current density $\left(i_{\mathrm{c}}\right)$ on the structure and capacitive performance of $\mathrm{MnO}_{2}$ electrodes has been studied. By simply modulating $i_{\mathrm{c}}$, either crystalline ( $\delta$-phase) or amorphous $\mathrm{MnO}_{2}$ electrodes are obtained. Specific capacitance values ranging from 170 up to $300 \mathrm{~F} \mathrm{~g}^{-1}$ at $1 \mathrm{~A} \mathrm{~g}^{-} 1$ are achieved depending on $i_{\mathrm{c}}$. Electrodeposition has shown to be a versatile (thin or thick), efficient (high current efficiencies can be obtained), binder-free and room-temperature technique to produce $\mathrm{MnO}_{2}$ electrochemical capacitor electrodes.

\section{Acknowledgements}

The authors would like to acknowledge FCT for financial support under the projects M-ERA.NET/0002/2012, M-ERA.NET/ 0004/2014 and PEst-OE/QUI/UI0100/2013. We also thank Prof. Teresa Duarte and Prof. Luis Santos (CQE/IST) for XRD and Raman facilities, respectively. We are indebted to Professor John Miller (JME, Inc., USA) that kindly reviewed the manuscript.

\section{References}

1 Y.-S. Ding, X.-F. Shen, S. Sithambaram, S. Gomez, R. Kumar, V. M. B. Crisostomo, S. L. Suib and M. Aindow, Chem. Mater., 2005, 17, 5382-5389.
2 A. R. Armstrong and P. G. Bruce, Nature, 1996, 381, 499-500.

3 F. Cheng, J. Zhao, W. Song, C. Li, H. Ma, J. Chen and P. Shen, Inorg. Chem., 2006, 45, 2038-2044.

4 M. Lua, S. Kharkwal, H. Y. Ng and S. F. Y. Li, Biosens. Bioelectron., 2011, 26, 4728-4732.

5 X. Li, B. Hu, S. Suib, Y. Lei and B. Li, J. Power Sources, 2010, 195, 2586-2591.

6 W. Wei, X. Cui, W. Chena and D. G. Ivey, Chem. Soc. Rev., 2011, 40, 1697-1721.

7 G.-R. Xu, X.-P. Min, Q.-L. Chen, Y. Wen, A.-P. Tang and H.-S. Song, J. Alloys Compd., 2017, 691, 1018-1023.

8 S.-K. Park, A. Jin, S.-H. Yu, J. Ha, B. Jang, S. Bong, S. Woo, Y.-E. Sung and Y. Piao, Electrochim. Acta, 2014, 120, 452-459.

9 A. Sarkar, A. K. Satpati, V. Kumar and S. Kumar, Electrochim. Acta, 2015, 167, 126-131.

10 Y. Chae, J. K. Lee and W. Choi, J. Electroanal. Chem., 2014, 730, 20-25.

11 K. Neishi, S. Aki, K. Matsumoto, H. Sato, H. Itoh, S. Hosaka and J. Koike, Appl. Phys. Lett., 2008, 93, 032106.

12 T. Tanimoto, H. Abe, K. Tomono and M. Nakayama, ECS Trans., 2013, 50, 61-70.

13 J. W. Dini, Plat. Surf. Finish., 1993, 80, 26-29.

14 G. M. Jacob and I. Zhitomirsky, Appl. Surf. Sci., 2008, 254, 6671-6676.

15 CRC Handbook of Chemistry and Physics, ed. D. R. Lide, CRC Press/Taylor and Francis, Boca Raton, FL, 89th edn, 2009.

16 T. Yousefia, A. N. Golikand, M. H. Mashhadizadeh and M. Aghazadeh, J. Solid State Chem., 2012, 190, 202-207.

17 M. A. Cheney, S. W. Joo, A. Banerjee and B.-K. Min, J. Colloid Interface Sci., 2012, 379, 141-143.

18 X. Hu, X. Lin, Z. Ling, Y. Li and X. Fu, Electrochim. Acta, 2014, 138, 132-138.

19 Y. Su and I. Zhitomirsky, Adv. Eng. Mater., 2014, 16, 760-766. 20 H. Wang, C. M. B. Holt, Z. Li, X. Tan, B. S. Amirkhiz, Z. Xu, B. C. Olsen, T. Stephenson and D. Mitlin, Nano Res., 2012, 5, 605-617.

21 L. Mai, H. Li, Y. Zhao, L. Xu, X. Xu, Y. Luo, Z. Zhang, W. Ke, C. Niu and Q. Zhang, Sci. Rep., 2013, 3, 1718.

22 I. Atribak, A. Bueno-Lopez, A. Garcia-Garcia, P. Navarro, D. Frias and M. Montes, Appl. Catal., B, 2010, 93, 267-273.

23 C. Julien, M. Massot, R. Baddour-Hadjean, S. Franger, S. Bach and J. P. Pereira-Ramos, Solid State Ionics, 2003, 159, 345-356.

24 B. E. Conway, J. Electrochem. Soc., 1991, 138, 1539-1548.

25 J. Wei, N. Nagarajan and I. Zhitomirsky, J. Mater. Process. Technol., 2007, 186, 356-361.

26 A. Cross, A. Morel, A. Cormie, T. Hollenkamp and S. Donne, J. Power Sources, 2011, 196, 7847-7853.

27 J. N. Broughton and M. J. Brett, Electrochim. Acta, 2005, 50, 4814-4819.

28 Q. Lu, J. G. Chen and J. Q. Xiao, Angew. Chem., Int. Ed., 2013, 52, 1882-1889.

29 R. Della Noce, S. Eugénio, M. Boudard, L. Rapenne, T. M. Silva, M. J. Carmezim, S. W. Donne and M. F. Montemor, RSC Adv., 2016, 6, 15920-15928. 